\section{Magnetic Resonance Imaging of Water in Flower Buds of Blueberry}

\author{
Lisa J. Rowland ${ }^{1}$, Dehua Liu', Merle M. Millard ${ }^{2}$, and \\ Michael J. Line'2. \\ Beltsville Agricultural Research Center Agricultural Research Service, \\ Beltsville, MD 20705
}

Additional index words. Vaccinium corymbosum, dormancy, chilling requirement, nuclear magnetic resonance (NMR)

\begin{abstract}
Dormant and chilled highbush blueberry (Vaccinium corymbosum L.) flower buds were examined by magnetic resonance imaging (MRI). T2 relaxation times of water molecules were too short to create images from flowers within buds that were dormant and had received no chilling, but they were sufficiently long to create images from buds that had their chilling requirement satisfied. To explain the change in relaxation times, we concluded that water is present in a motionally restricted form in flowers of dormant blueberry buds and in a freer form in flowers of buds after the chilling requirement has been satisfied. $\mathrm{T} 2$ values for chilled blueberry buds indicated that one population of water molecules with a detectable $T 2$ time was present in flowers of chilled buds with a relaxation time of $\approx 8$ to $15 \mathrm{~ms}$.
\end{abstract}

The amount of low temperature required to overcome endodormancy (Lang et al., $1985)$ in fruit trees is referred to as the chilling requirement. The chilling requirement is generally defined as the number of hours between $\approx 2.5$ and $9 \mathrm{C}$, which yields $\geq 50 \%$ budbreak after 3 weeks at 20C (Gianfagna and Mehlenbacher, 1985; Young and Werner, 1985).

Little is known about the physiological or biochemical changes that occur during chilling or that mark completion of the chilling requirement. Nuclear magnetic resonance measurements have been used to study water and water interactions in biological systems, and, recently, magnetic resonance imaging (MRI) has been used to investigate the state of water in leaf buds of apple (Malus domestica Borkh.) before and after satisfaction of the chilling requirement (Faust et al., 1991) and during maturation of barley (Hordeum

Received for publication 17 June 1991. Accepted for publication 2 Dec. 1991. The cost of publishing this paper was defrayed in part by the payment of page charges. Under postal regulations, this paper therefore must be hereby marked advertisement solely to indicate this fact.

${ }^{\mathrm{I}}$ Fruit Laboratory.

${ }^{2}$ Environmental Chemistry Laboratory. vulgare L.) and soybean [ Glycine max (L.) Merr.] seeds (Kano et al., 1990). Magnetic resonance imaging primarily detects differences in proton relaxation time (T1 and T2) of water. $\mathrm{T} 1$, or the spin-lattice relaxation time, relates to the relaxation of nuclei after radiofrequency stimulation by dissipation of their excess energy to the surroundings or lattice. $\mathrm{T} 2$, or the spin-spin relaxation time, relates to the transfer of energy from one nucleus to its neighbor. MRI images of apple buds, based on both T1 and T2 factors (Faust et al., 1991) and based on the T2 factor alone (M.M. Millard et al., unpublished), reveal that water is undetectable in dormant buds but is detectable in buds after satisfaction of the chilling requirement. Because water accounts for $\approx 50 \%$ of the weight of both dormant and chilled buds (Faust et al., 1991), MRI results suggest that the $\mathrm{T} 2$ relaxation time of water in dormant buds is too short to be measured. Water may be free or may interact with biological macromolecules either by hydrogen bonds between polar groups or hydrophobic bonds between nonpolar residues (Fullerton and Cameron, 1988). Water has a much shorter relaxation time when such interactivity is present than when water is free because of its restricted motion. Thus, the shorter relaxation time of water in un- chilled dormant apple buds is attributed to the presence of water with restricted motion in dormant buds vs. freer water in chilled buds. Similar results have been reported for barley and soybean seeds (Kano et al., 1990), in which the T2 relaxation time of water decreases as the seeds mature and accumulate more polysaccharides and proteins.

We are using blueberry plants to study physiological and biochemical changes induced in flower buds by chilling because the plants are small relative to most fruit trees. Consequently, they can be more easily maintained in a controlled environment such as a cold room or greenhouse. We have used the MRI technique described for apple leaf buds (Faust et al., 1991) to investigate the state of water in blueberry flower buds before and after chilling. Several tetraploid highbush blueberry cultivars were studied -'Georgiagem' and 'Gulfcoast', which have a relatively low chilling requirement of $\approx 400 \mathrm{~h}$ (Austin and Bondari, 1987; L.J.R., unpublished), and 'Bluecrop', 'Bluejay', and 'Duke', which have a relatively high chilling requirement of $\approx 1000 \mathrm{~h}$ (Draper et al., 1987; Moulton and Andersen, 1978; Norvell and Moore, 1982).

Plants of 'Georgiagem', 'Gulfcoast', and 'Bluecrop', were kept in a heated greenhouse until about 1 Jan. to ensure plants were
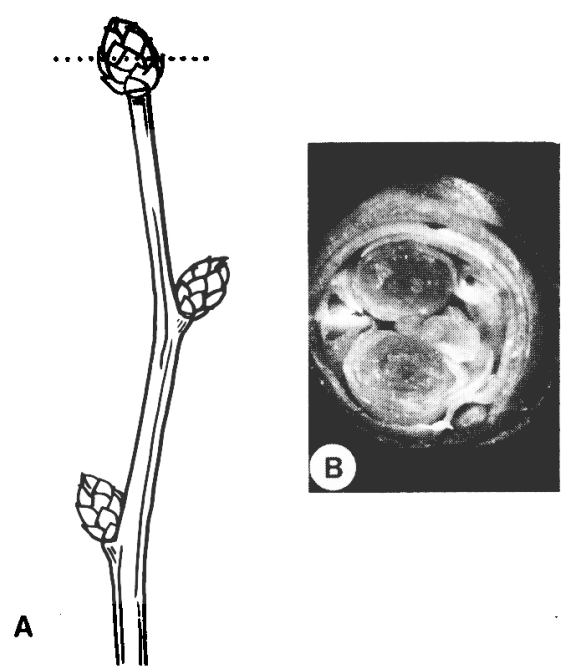

Fig. 1. Schematic illustration of imaging plane through the terminal flower bud (A) and actual cross section of blueberry flower bud revealing the florets $(\mathbf{B})$. 


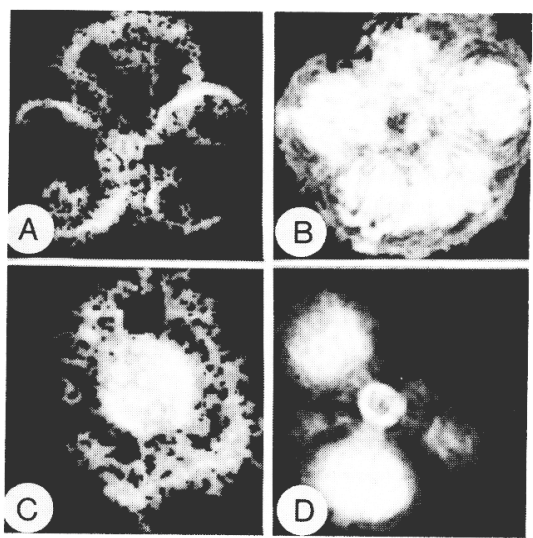

Fig. 2. Magnetic resonance images of unchilled $(\mathbf{A}, \mathbf{C})$ and chilled $(\mathbf{B}, \mathbf{D})$ flower buds of blueberry cultivars Georgiagem and Gulfcoast, respectively.

dormant but had not acquired any chilling. The temperature in the heated greenhouse never dropped below 18C. Three to four control shoots $\left(0^{\prime}\right.$ 'shoots) were collected from each plant. After they were collected, the plants were moved to a cold room maintained at $7 \mathrm{C}$. Three to four shoots were collected from each of these plants, from fieldgrown plants, or from plants in our unheated greenhouse after they had received a minimum of $1000 \mathrm{~h}$ below 7.2C, thus ensuring that the chilling requirement of all cultivars had been satisfied. Chilling hours for fieldgrown plants and plants in our unheated greenhouse were calculated by measuring the number of hours below 7.2C with a biophenometer.

After shoots were collected, they were placed in distilled water at 20 to $24 \mathrm{C}$ for 24 $\mathrm{h}$ before MRI analysis. MRI analysis was performed by weighting the T2 factor as done for apple leaf buds (M.M. Millard et al., unpublished). Shoots were placed in MRI tubes for imaging. A 15 -mm-diameter insert was used in the Bruker MRI imaging probe (Bruker Instrument, Manning Park, Billerica, Mass.). Single slice, single echo images were used with a matrix size of $256 \times 256$ with a spatial resolution of $20 \times 20 \times 500$ $\mathrm{pm}$. Data acquisition time was $2 \mathrm{~h}$. TE (echo delay time) was $11.2 \mathrm{~ms}$ and TR (pulse repetition time) was $1.6 \mathrm{sec}$.

Image slices were taken perpendicular to the axis of the shoot through the midpoint of the terminal bud (Fig. 1). Hard copy images were obtained using a Sony video graphic printer UP-811.

T2 times for chilled buds were calculated by plotting the energy decay of the measurable signal through eight echoes and using a single component fit analysis, $\mathrm{y}=\mathrm{k}_{0} \mathrm{e}^{-t / 2}$ $+\mathrm{k}_{x}$, where $\mathrm{y}$ refers to the intensity of the signal, $\mathrm{t}$ refers to the time, and $\mathrm{k}$ is a constant (Bevington, 1969).

The moisture content of dormant and chilled buds of 'Georgiagem' was determined by weighing buds before and after drying at $80 \mathrm{C}$ for $48 \mathrm{~h}$.

Proton signals of the low-chilling cultivars (Georgiagem and Gulfcoast) were detected
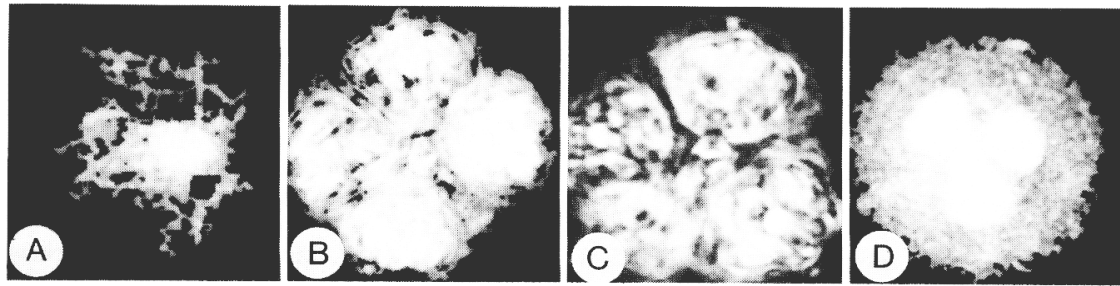

Fig. 3. Magnetic resonance images of unchilled (A) and chilled (B) flower buds of blueberry cultivars and chilled flower buds of blueberry cultivars Bluejay (C) and Duke (D).

\section{DUKE}

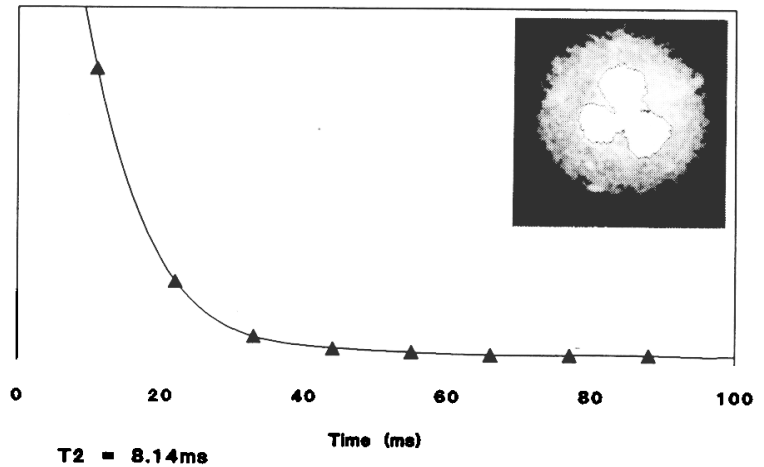

BLUECROP

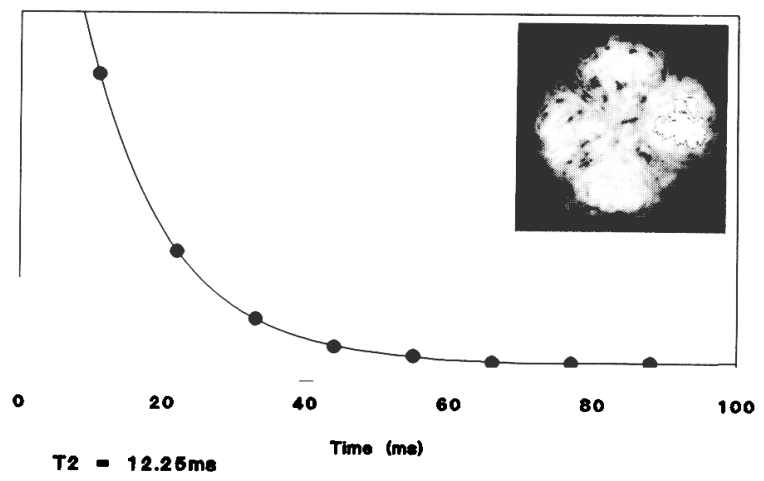

Fig. 4. T2 calculations for chilled 'Duke' (A) and 'Bluecrop' (B) flower buds shown in Fig. 3. T2 values were calculated from the areas outlined on each image. The areas were chosen because they were of uniform density and representative of flowers within the buds. The curves represent relative energy decay values (magnetic strength measured in Tesla) through eight echoes as a function of time. The calculated $\mathrm{T} 2$ values are shown.

only from the rachis and bud scales (Fig. 2 A,C) but not the flowers of unchilled buds. However, water, with a detectable T2 time, was observed within the flowers, bud scales, and rachis of chilled buds (Fig. 2 B,D). These results are similar to those reported for apple leaf buds (Faust et al., 1991). The moisture content of flower buds, determined for 'Georgiagem' by dry weight, was 59\% for dormant buds and $57 \%$ for chilled buds, i.e., about the same before and after satisfaction of the chilling requirement. We attribute our inability to detect water within flowers of the 0 ' buds, therefore, to the presence of water in a form having a T2 time that is too short to be measured.

Proton profiles of unchilled (Fig. 3A) and chilled (Fig. 3B) buds of the high-chilling cultivar Bluecrop and chilled buds of highchilling cultivars Bluejay (Fig. 3C) and Duke (Fig. 3D), also revealed that water with a measurable $\mathrm{T} 2$ time was not detectable in flowers of unchilled buds but was detectable in flowers of chilled (> $1000 \mathrm{~h}$ ) buds.

Our results indicate that water is present in a motionally restricted form in flowers of dormant blueberry buds, resulting in a short $\mathrm{T} 2$ relaxation time, and in a relatively freer form in flowers after the chilling requirement has been satisfied, resulting in a relatively longer T2 time. An alternative explanation is that the water in unchilled dormant buds is concentrated in the bud scales and rachis and that chilling induces mobilization of water into the flowers themselves. However, because the echo and repetition times for im- 
aging were chosen to optimize detection of water, we believe if all the water in unchilled buds ( $\gg 60 \%$ by weight) were concentrated in the bud scales and rachis regions, the intensity of the MRI signal would be much greater in these regions of unchilled buds than in those of chilled buds, rather than being about the same, as we found. Conversely, the transition of water from a free form to a motionally restricted form has been observed during maturation of barley and soybean seeds (Kano et al., 1990). Thus, analogous changes may occur during development of dormancy in leaf and flower buds and during maturation of certain types of seeds.

Actual T2 times for chilled buds of 'Georgiagem', 'Gulfcoast', 'Bluecrop', 'Bluejay', and 'Duke' were determined. T2 times were calculated by plotting the decay of the energy of the measurable signals through eight echoes and using a single component fit analysis that gave one overall $\mathrm{T} 2$ time. The curves generated by assuming one overall $\mathrm{T} 2$ time accurately predicted the actual values. The T2 time calculated for 'Duke' was 8.14 $\mathrm{ms}$ and for 'Bluecrop' was $12.25 \mathrm{~ms}$ (Fig. 4). These measurements and calculations were repeated for a second bud of 'Bluecrop' and 'Duke' and for buds of 'Bluejay', 'Georgiagem', and 'Gulfcoast'. T2 times for all cultivars ranged from 8.14 to $14.65 \mathrm{~ms}$. These results were similar to those from apple leaf buds in which T2 times averaged $\gg 12.5 \mathrm{~ms}$ (M.M. Millard et al., unpublished). Estimates of T2 times of water in sand and water mixtures range from 54 to $76 \mathrm{~ms}$ (McFall et al., 1990). These measurements should reflect T2 times of free water. Thus, our data suggest that the bulk of water in flowers of chilled buds is somewhat motionally restricted although it has a longer T2 time, or is freer, than the water in flowers of dormant buds. We emphasize, however, that the percentage of water that undergoes this transition could not be determined from our MRI analysis. We believe, however, that the observable water in chilled buds probably accounts for $30 \%$ to $50 \%$ of the total tissue weight because, in the analysis of standards where the water was known to account for $£ 2070$ of the tissue by weight, MRI was not possible within the time span used for these experiments.

\section{Literature Cited}

Austin, M.E. and K. Bondari. 1987. Chilling how requirement for flower bud expansion of two rabbiteye and one highbush blueberry shoots. HortScience 22:1247-1248.

Bevington, P.R. 1969. Data reduction and error analysis for the physical sciences. McGraw-Hill, New York.

Draper, A., G. Galletta, G. Jelenkovic, and N. Versa. 1987. 'Duke' highbush blueberry. HortScience 22:320.

Faust, M., D. Liu, M.M. Millard, and G.W. Stutte. 1991. Bound versus free water in dormant apple buds: A theory for endodormancy. HortScience 26:887-890.

Fullerton, G.D. and I.L. Cameron. 1988. Relaxation of biological tissue, p. 115-151. In: F. W. Wherly, D. Shaw, and J.B. Kneeland (eds.). Biomedical magnetic resonance imaging. Prin- ciples, methodology and applications. $\mathrm{VCH}$ Publishers, New York.

Gianfagna, T.J. and S.A. Mehlenbacher. 1985. Importance of leaf requirement for bud break and time of flowering in apple. HortScience 20:909-911.

Kane, H., N. Isida, T. Kobayashi, and M. Koizumi. 1990. 'H-NMR imaging analysis of changes of free water distribution barley and soybean seeds during maturation. Jpn. J. Crop Sci. 59:503-509.

Lang, G. A., J.D. Early, N.J, Arroyave, R.L. Darnell, G.C. Martin, and G.W. Stutte. 1985. Dormancy: Toward a reduced universal terminology. HortScience 20:809-811.

McFall, J. S., G.A. Johnson, and P.J. Kramer.
1990. Observation on water depletion region surrounding loblolly pine roots by magnetic resonance imaging. Proc. Natl. Acad. Sci. 87:12031207.

Moulton, J.E. and R.L. Andersen. 1978. Bluejay-a new blueberry variety. Michigan State Univ. Agr. Expt. Sta. Res. Rpt. 355.

Norvell, D.J. and J.N. Moore. 1982. An evaluation of chilling models for estimating rest requirements of highbush blueberries (Vaccinium corymbosum L.). J. Amer. Soc. Hort. Sci. 107:54-56.

Young, E. and D.J. Werner. 1985. Chill unit and growing degree hour requirements for vegetative bud break in six apple root stocks. J. Amer. Soc. Hort. Sci. 110:411-413. 